\title{
Os espaços socioeducativos da escola e a reconfiguração da pedagogia (educação) social na intervenção escolar
}

\author{
Ernesto Candeias
}

\begin{abstract}
Resumo
Reivindicamos um novo papel à pedagogia social e à educação social no espaço socioeducativo escolar, devido ao surgimento de problemáticas sociais no seio da escola. Essa recuperação do escolar no processo de reconfiguração da pedagogia social, acostumada a intervir no âmbito da educação não-formal, converte a aquela num campo de reflexão da intervenção sobre os problemas sociais e educativos que nela ocorrem. Pretendemos com os nossos propósitos contribuir para a reconfiguração da pedagogia social e da ação da educação social na escola, em articulação com a intervenção comunitária. Na base de uma metodologia hermenêutica norteamo-nos pelos seguintes objetivos, os quais coincidem com os dois pontos estruturais do texto: analisar na realidade atual algumas evidências que exigem respostas socioeducativas no âmbito da pedagogia social e educação social; reconfigurar a pedagogia social como uma pedagogia social escolar, no âmbito das Ciências da Educação, de modo a compreender a intervenção escolar, através da educação social; compreender a (inter) relação entre a pedagogia social (âmbito teórico) e a educação social (âmbito prático), especialmente ao nível da prática pedagógico-social na escola; determinar o papel da pedagogia social no contexto escolar, os desafios e respostas socioeducativas dados pela escola. Sabemos que os programas de intervenção nos espaços socioeducativos escolares exigem a colaboração relacional 'escola-família-comunidade' e a (re)construção de uma pedagogia social inclusiva, equitativa, para a formação da cidadania, resolução de conflitos e de problemas sociais e educativos.
\end{abstract}

\section{Palavras-chave:}

espaços socioeducativos; novas realidades escolares; pedagogia social; educação social; pedagogia escolar. 


\section{The socio-educational spaces of the school and the reconfiguration social pedagogy (education) in school intervention}

Abstract: We demand a new role to social pedagogy and social education in the socio-educational school space, due to the emergence of social problems within the school. This recovery of the schoolgirl in the process of reconfiguration of social pedagogy, accustomed to intervene in the context of non-formal education, converts it into a field of reflection of the intervention on the social and educational problems that occur in it. We intend with our purposes to contribute to the reconfiguration of social pedagogy and the action of social education at school, in conjunction with community intervention. Based on a hermeneutic methodology, we are based on the following objectives, which coincide with the two structural points of the text: to analyze in the current reality some evidence that requires socio-educational responses in the context of social pedagogy and social education; reconfigure social pedagogy as a social pedagogy of education, in order to understand school intervention, through social education; understand the (inter) relationship between social pedagogy (theoretical scope) and social education (practical scope), especially at the level of pedagogical-social practice at school; determine the role of social pedagogy in the school context, the challenges and socio-educational responses given by the school. We know that intervention programs in school socio-educational spaces require relational collaboration 'school-family-community' and the (re)construction of an inclusive, equitable social pedagogy for the formation of citizenship, conflict resolution and social and educational problems.

Keywords: socio-educational spaces; new school realities; social pedagogy; social education; school pedagogy.

\section{Les espaces socio-éducatifs de l'école et la reconfiguration de la pédagogie sociale (éducation) dans l'intervention scolaire}

Résumé: Nous exigeons un nouveau rôle de la pédagogie sociale et de l'éducation sociale dans l'espace scolaire socio-éducatif, en raison de l'émergence des problèmes sociaux au sein de l'école. Cette récupération de l'écolier en cours de reconfiguration de la pédagogie sociale, habituée à intervenir dans le contexte de l'éducation non formelle, la transforme en un champ de réflexion de l'intervention sur les problèmes sociaux et éducatifs qui s'y produisent. Nous avons l'intention, de contribuer à la reconfiguration de la pédagogie sociale et à l'action de l'éducation sociale à l'école, en conjonction avec l'intervention communautaire. Sur la base d'une méthodologie herméneutique, nous nous fondons sur les objectifs suivants, qui coïncident avec les deux points structurels du texte : analyser dans la réalité actuelle certaines preuves qui nécessitent des réponses socio-éducatives dans le contexte de la pédagogie sociale et de l'éducation sociale; reconfigurer la pédagogie sociale comme pédagogie sociale de l'éducation, afin de comprendre l'intervention scolaire, par l'éducation sociale; comprendre la relation (inter) entre la pédagogie sociale (portée théorique) et l'éducation sociale (portée pratique), en particulier au niveau de la pratique pédagogique et sociale à l'école; déterminer le rôle de la pédagogie sociale dans le contexte scolaire, les défis et les réponses socio-éducatives données par l'école. Nous savons que les programmes d'intervention dans les espaces socio-éducatifs scolaires exigent une collaboration relationnelle "école-famille-communauté» et la (re)construction d'une pédagogie sociale inclusive et équitable pour la formation de la citoyenneté, la résolution des conflits et les problèmes sociaux et éducatifs.

Mots-clés : espaces socio-éducatifs; nouvelles réalités scolaires; pédagogie sociale; éducation sociale; pédagogie scolaire.

\section{Los espacios socioeducativos de la escuela y la reconfiguración de la pedagogía social (educación) en la intervención escolar}

Resumen: Reivindicamos un nuevo papel a la pedagogía social y a la educación social en los espacios socioeducativos escolares, debido al surgimiento de problemas sociales en la escuela. Esa recuperación de la escuela en el proceso de reconfiguración de la pedagogía social, acostumbrada a intervenir en el contexto de la educación no formal, convierte aquella en un campo de reflexión dela intervención sobre los problemas sociales y educativos que se producen en ella. Pretendemos con nuestros propósitos contribuir para la reconfiguración de la pedagogía social y de la acción de la educación social en la escuela, articulada con la intervención comunitaria. Sobre la base de una metodología hermenéutica, nos basamos en los siguientes objetivos, que coinciden con los dos puntos estructurales del texto: analizar en la realidad actual algunas evidencias que requieren respuestas socioeducativas en el contexto de la pedagogía social y la educación social; reconfigurar la pedagogía social como pedagogía social escolar, de modo a entender la intervención escolar, a través de la educación social; comprender la relación (inter) entre la pedagogía social (alcance teórico) y la educación social (alcance práctico), especialmente al nivel de la práctica pedagógica-social en la escuela; determinar el papel de la pedagogía social en el contexto escolar, los desafíos y respuestas socioeducativas dadas por la escuela. Sabemos que los programas de intervención en los espacios socioeducativos escolares requieren la colaboración "escuela-familia-comunidad" y la (re)construcción de una pedagogía social inclusiva y equitativa para la formación de la ciudadanía, la resolución de conflictos y los problemas sociales y educativos.

Palabras-clave: espacios socioeducativos; nuevas realidades escolares; pedagogía social; educación social; pedagogía escolar. 


\section{Introdução}

Assistimos a um cenário de mudanças e impactos na socialização e educação dos indivíduos, sobretudo das novas formas de aprendizagem e sustentabilidade de novas possibilidades pedagógicas, segundo os desafios e a complexidade da própria sociedade (Morin, 2001). A crise que vivemos nos últimos tempos, especialmente no âmbito económico e social, tem incrementado as desigualdades sociais, educativas, culturais, médico-sanitárias ou assistenciais, tecnológicas e digitais, aspetos que implicam a ação da pedagogia social (a partir de agora PS) e da educação social (a partir de agora ES) com a pouca efetividade de projetos/programas socioeducativos com a família, com a comunidade, as crianças/jovens (risco), idosos, imigrantes e refugiados, grupos étnicos, toxicodependentes, sem abrigo, etc. (Ruiz, 2003). A PS e a ES devem refletir sobre o surgimento de (novas) questões, situações e conflitos sociais humanos (Pérez Serrano, 2003). A interação do 'pedagógico-social' implica uma necessidade de abertura da educação à vida em toda a sua diversidade na comunidade (Núñez, 2002), inclusive no espaço escolar. A ES (objeto e prática da PS) ampara-se na conceção do social, como campo de problemáticas sociais e necessidades que afetam a escola, convergindo para o espaço escolar as suas intervenções, na base de tratamento socioeducativo, ações de mediação, de inclusão, de adaptação e transmissão cultural (interculturalidade), que constituem um serviço e um direito social de legitimação de cidadania (Timóteo, 2013). A dificuldade económica e social, incrementou a desigualdade social, educativa, cultural, médico-sanitária e/ou assistencial e a digital/ tecnológica, aspetos que implicam a ação da PS e a ES com a comunidade, a família e escola (Gramigna, 2003; Ruiz, 2003). Perante estas novas situações, a PS não se fundamentou na dimensão socioeducativa para as instituições escolares, sabendo que a missão da escola vai mais além do significado da escolarização. De facto, a PS e ES analisam os impactos socioeducativos nos sujeitos da educação, a sua socialização, as consequências do insucesso e abandono escolar, as problemáticas sociais (indisciplina, violência e inadaptação escolar), incidentes nos espaços socioeducativos da escola, as quais devem dar respostas a esses mesmos problemas sociais, que se convertem igualmente em educativos (March, 2007).

Tendo em conta essas problemáticas sociais na escola, devemos reivindicar o papel da PS e da ES no espaço socioeducativo escolar. Ou seja, uma das dimensões atuais será a função socioeducativa da PS na escola, através da ES. Essa recuperação do escolar no processo de reconfiguração da PS converte esse espaço numa reflexão e intervenção sobre os problemas sociais e educativos que aí ocorrem, muitos deles oriundos do exterior. Neste sentido, todos os programas de intervenção socioeducativa na escola exigem a colaboração 'escola-família-comunidade' e a (re)construção 
de uma PS inclusiva, equitativa, de formação da cidadania e na ação sobre conflitos e problemas sociais e educativos dos alunos (Merino, 2005).

$\mathrm{Na}$ base dos nossos propósitos de reconfigurar a PS ao contexto escolar e à intervenção socioeducativa por parte da ES, estabeleceremos os seguintes objetivos, que coincidem com os dois pontos estruturais do texto: Analisar na realidade atual algumas evidências que exigem respostas no âmbito da PS e da ES nos espaços socioeducativos; Reconfigurar a PS como uma pedagogia social escolar, no âmbito das Ciências da Educação, de modo a compreender a intervenção escolar ( e social), através da ES; Compreender a (inter) relação entre a PS (âmbito teórico) e a ES (âmbito prático), especialmente ao nível da prática pedagógico-social na escola; Determinar o papel da PS no contexto escolar e os desafios e respostas socioeducativas dados pela escola.

Servimo-nos de um quadro teórico-conceptual norteado por um conjunto de estudos de especialistas sobre PS e ES, que nos ilustram com as suas reflexões a aprofundar esses conceitos, as áreas ou campos de intervenção nos novos espaços e tempos atuais, especialmente no contexto escolar, sendo exemplos: os enfoques e estudos diversificados de J.A. Caride (2000, 2009), A. J. Colom (1983, 1987), A. Petrus (2000), M. March (2007) e M. March \& C Orte (2014), Quintana-Cabanas (2001), J. Ortega (2005), A. Parcerisa Aran (2008), G. Pérez Serrano (2003), C. Ruiz (2003), X. Úcar (2013), J. Trilla (2000, 2003), J. V. Merino (2005), da latino-americana Violeta Núñez (2002) e, ainda, de A. Gramigna (Universitat de Ferrara) e os portugueses Adalberto D. Carvalho e I. Baptista (2004) e Martins (2013), entre outros.

A nossa argumentação baseia-se numa metodologia hermenêutica (analítica e crítica) à PS e ES no seu papel de intervenção socioeducativa na escola, tendo em conta os novos espaços de aprender e a sua articulação com os escolares (Caride, 2005). Os espaços e tempos na atualidade marcam a pedagogia no âmbito social, seja ao nível escolar, não-escolar e comunitário. A própria globalização fez proliferar 'espaço e tempo' no aprender e nas formas de conviver, produzindo novas caraterísticas e áreas de ação ou intervenção, o que fez desviar o(s) discurso(s) pedagógico(s) da escola e centraliza-lo(s) na satisfação e necessidades sociais e culturais de formação do indivíduo (Martins, 2013). De facto, os 'novos' espaços e tempos de aprender estão em função do que era 'habitual ou tradicional', reconhecendo que esses novos espaços/tempos surgiram devido às novas formas de aprendizagem em contextos diversos e com vários meios disponíveis para os indivíduos. O surgimento desses 'novos' espaços implica uma reflexão sobre os tempos da Pedagogia nesses contextos ou situações formais e não formais (Gramigna, 2003). Neste sentido, a PS tem emergido como uma teoria e categoria favorecedora de uma renovação de conceptualização para o currículo, para os professores, educadores sociais, comunitários e outros técnicos (Petrus, 2000). 


\section{As evidências na realidade para novas exigências da PS e ES}

Nas últimas décadas, as sociedades estão num processo de mudança social, em todos os setores, por exemplo: nos problemas da convivência e do desenvolvimento humano e vida comunitária; na ação de movimentos (civis) e redes sociais com participações específicas; na emergência de questões ambientais e socioeducativas que requerem consciencialização planetária; na transformação do mercado de trabalho e o impacto das novas tecnologias na vida das pessoas, etc. Estes e outros aspetos constituem campos de preocupação dos diversos atores, muito devido ao surgimento de novos espaços e novos tempos para aprender a aprender, para além de novos discursos que implicam novas perguntas conceptuais, pedagógicas e metodológicas perante os desafios das mudanças, em especial na escola (Baena; Sáenz; Quintana-Cabañas, 2002). No seguimento destas alusões, destacamos algumas evidências (indícios) na sociedade que pressionam as instituições educativas e a própria educação e a pedagogia na procura de (novas) respostas da escola e da comunidade (Morin, 2001).

A eclosão da ES tem coincidido com o aparecimento de certas transformações, por exemplo: índole económica (economia de produção, revolução tecnológica, reconversão e especialização profissional), produzindo bolsas de pobreza, excluídos, marginalizados e desprotegidos necessitados de intervenção; índole relacional e de organização social (quebra das redes tradicionais de comunicação e de relação, produzindo o efeito 'cocoon'); índole axiológico (o consumismo, a solidão, o individualismo, a violência e transgressão dos direitos humanos, como expressões espontâneas, o desaparecimento dos referentes tradicionais familiares, a perda do sentido coletivo e de ação do grupo, a indiferença e a ansiedade perante as mudanças sociais) (Quintana-Cabana, 2001). Todas estas alterações contribuem para que a PS e a ES entrem no contexto escolar, e para tal, exige-se uma reconfiguração e/ou redefinição da PS e da ES à sua conceptualização tradicional, pois historicamente elas continuam a intervir nos setores de excluídos e incapazes de inclusão e adaptação, na socialização e interculturalidade.

Indicamos algumas evidências existentes na sociedade atual que desafiam, por um lado, a procura de respostas e medidas socioeducativas pela escola e, por outro lado, a reconfiguração da PS no contexto escolar (pedagogia social escolar).

- Evidência: Manifestações, pressupostos e/ou controvérsias na sociedade sobre a educação. Qualquer pressuposto ou controvérsia sobre questões sociais pressionam as instituições educativas e a própria educação/pedagogia a adotar respostas, intervindo de forma socioeducativa nos comportamentos dos alunos, perante várias situações e problemáticas sociais e educativas. Em seguida indicamos algumas evidências existentes na sociedade que desafiam e requerem respostas da escola e uma reconfiguração da PS e ES ao nível da reflexão e intervenção no âmbito escolar. 
- Evidência: As contradições e dilemas sobre a escola. Existe no seio da escola necessidade de uma reconstrução adequada aos novos tempos, já que ela não apresenta respostas e medidas (projetos, programas) eficazes para situações e problemas práticos da vida quotidiana dos alunos (Timóteo, 2013). Ou seja, a escola deve: renovar-se e adaptar-se às suas funções reais articulando a perspetiva das aprendizagens formais com as não formais (Trilla et al., 2003); adotar medidas eficazes (mediação) para com as situações de conflito social como a violência e indisciplina escolar, de inadaptação social e para questões de não-inclusão, diversidade cultural (interculturalidade); promover a educação parental e a intergeracional; adequar-se às exigências do mercado de trabalho, a partir de uma formação profissional mais efetiva (orientação, qualificação) e de envolvimento do tecido empresarial e social; ampliar as possibilidades da educação escolar como instrumento para a igualdade social (âmbito da cultura e emancipação); rever a relação da 'Escola-Família' num maior envolvimento no processo educativo dos alunos; aprofundar a relação 'escola-meios de comunicação e digitais/tecnológicos' (competências mediáticas); reconsiderar a educação para as emoções e as estratégias afetivo-comportamentais para desenvolver habilidades sociais e emocionais; etc. Nesta renovação da escola, a PS e a ES são preponderantes no âmbito da ação e/ou intervenção socioeducativa, em sintonia com áreas de colaboração da comunidade, no reforço de aquisição de (novas) competências básicas e metodológicas essenciais aos alunos (aprendizagem autónoma, educação emancipatória e 'empowerment') e, ainda, na compreensão da realidade atual (educação ambiental) e dos impactos das pandemias (educação para a saúde), como a que atravessamos.

Se admitimos a interceção da PS no contexto escolar, e sabendo da limitação do papel da escola, deve-se recorrer a programas/projetos de integração e inserção de diversos coletivos, por exemplo de crianças/jovens em risco, de modo a permitir a sua convivência real na comunidade (modelo de relação social ativo e participante) e a sua inclusão. Desta maneira, cabe à escola definir as suas funções sociais na construção de uma nova cultura escolar baseada na colaboração com outras instituições sociais, em especial com a família e comunidade. É desejável, neste espaço socioeducativo, a construção de uma pedagogia (social) escolar, preponderante na relação entre 'Escola-ação da ES' assente na tríade: formação de professores e profissionais conhecedores das novas realidades (socialização) e da cultura escolar (problemas); implementação de medidas orientadas para a melhoria da convivência e para a construção de uma cidadania ativa, na base da orientação e da mediação socioeducativa nessa resolução de conflitos e problemáticas socioeducativas; fomento do trabalho cooperativo entre os profissionais (equipas) no seio escolar, em sintonia com os técnicos do município e das instituições da comunidade, no âmbito da prevenção e da promoção educativa e cultural. Perante estes pressupostos, apostamos, ao nível da ação/intervenção escolar e social, o processo de institucionalização da PS e da ES na escola (Caride, 2003).

- Evidência: Redefinição de discursos e fronteiras de conceptualização. Há necessidade de refazer ou reconsiderar os novos discursos pedagógicos de modo a reformar, 
modernizar e readaptar os sistemas educativos às exigências atuais e dar resposta aos desafios da sociedade (digital) cada vez mais complexa (Morin, 2001). A modernização tecnológica e respetivos avanços determinam o melhoramento de condições para aprender e a participação mais ativa da 'escola-família' e de outras instituições da comunidade (Caride, 2009). Nesta amálgama de discursos que atualmente nos invadem sobre novas formas de aprender surgem 'novos' conceitos relacionados com a pedagogia, com a educação de adultos e/ou permanente e a educação inter e transgeracional, a educação informal e não formal, a andragogia, a educação inclusiva, neuropedagogia, sociedade educativa ou de aprendizagem (cidade educativa), etc. (Petrus, 2000). Esta proliferação conceptual associada à Pedagogia partilha basicamente dois princípios gerais: a heterogeneidade (a educação é um fenómeno amplo, complexo e heterogéneo) e a globalidade (visão holística do processo educativo). Ora, é nesta perspetiva (global e integradora) de que todas as educações se entrelaçam na educação do educando, que devem ser entendidas pelas instituições educativas (Ruiz, 2003). Tudo isto implica o paradigma do meio educativo, em que toda a ação educativa se entende como relacional em meio/situação ou contexto determinado, seja na escola, família ou comunidade, sabendo que o meio influencia/condiciona e (re)configura a relação educativa/pedagógica e associa-se a outros elementos determinantes (novas tecnologias, aprendizagens não formais) (Colom, 1983).

Sabemos que a educação não escolar é muito ampla, com um repertório que vai desde: a vertente da formação ocupacional e profissional e/ou em contexto empresarial (estágios profissionais), a programas de qualificação e profissionalização (reconversão); a vertente do tempo livre (ócio, lazer) e da cultura (animação sociocultural, animação socioeducativa e comunitária); a vertente da educação social nas instituições educativas na resolução de problemas e de conflitos sociais; a vertente escolar com programas/projetos de envolvimento escola-família e da comunidade; a vertente da intergeracionalidade e multiculturalidade, com ações e programas envolvendo diferentes gerações e culturas. Todo este leque de educações e pedagogias primam pelo desenvolvimento da sociabilidade do(s) indivíduo(s) destacando-se a preocupação pelos grupos de conflito ou risco social e em contextos de educação não-formal e formal (Úcar, 2013).

- Evidência: Do dinamismo no conceito de PS e ES aos novos âmbitos de intervenção. Consideramos que o termo PS e a sua limitação conceptual é um âmbito disciplinar difícil de o fazer, pois depende o que entendemos por 'pedagogia' ou por 'pedagógico' e, principalmente, do que integra o qualificativo 'social', o qual abrange um espaço dinâmico, permeável e em contínua evolução. Se outrora a PS tinha bem diferenciado o seu âmbito/espaço de ação pedagógica, que não podia ser nem o familiar nem o escolar e, por isso, historicamente se designou na terminologia de Nöhl, por 'terceiro espaço' (ocupando-se de educação não-formal), atualmente há um entrelaçado, uma conexão e complexidade de interação dos espaços formais e não-formais na educação e no aprender (Caride, 2009). A PS trata da ciência da educação social, ou seja, 
"de una ciencia pedagógica que tiene por objecto de estudio la educación social, para posteriormente concretar los âmbitos, áreas o procesos en los que se proyectan su saber y competências teórico-prácticas" (Caride, 2005: 37). De facto, as definições de PS problematizam o que pode ser o 'social' (sociabilidade, socialização; intervenção em pessoas ou coletivos específicos em situação de conflito social; concretização em contextos e com meios educativos não-formais) que determinaram os âmbitos históricos da ES (educação especializada, educação de adultos ou permanente e animação sociocultural) com os respetivos perfis de profissionais (Nuñez, 2002).

O significado científico, disciplinar e intervencionista da PS apresenta uma conceptualização diversa proveniente da sua evolução histórica (desde Pestalozzi e do séc. XIX) e em função dos contextos e âmbitos em que se desenvolveu, tal como aconteceu à própria pedagogia. Desse conhecimento epistemológico sobre a PS estabeleceram-se diálogos e fronteiras com a educação não-formal e sociocomunitária, mas que hoje obrigam a incluir a educação formal ou escolar, devido à transferibilidade dessas problemáticas sociais ao contexto escolar (March; Orte, 2014).

Além disso, a ES tem assentado em três conceções, a saber: como motor de desenvolvimento da socialização da pessoa; como educação destinada a pessoas em situações de conflito social e/ou grupos em exclusão; como educação não-formal. Contudo, criticamente parece-nos nenhuma dessas aceções determinam o que é essencial em PS, sabendo que o seu objeto é a educação, que no mínimo reúne duas daquelas aceções (Trilla, 2000). Tradicionalmente, o âmbito de intervenção da ES é os contextos não escolares, pois a sua prioridade são pessoas e grupos em situação de risco e de conflito social e, por isso, incide numa educação 'não-formal'. Perante a realidade atual de educação ao longo da vida, a educação formal inclui todos os tipos de educação, desde a educação escolar, a educação contínua, educação social, educação ambiental, etc. deixando de ser adequado o uso de educação 'não-formal' referido à ES (Ortega, 2005). De facto, as definições (provisórias de conceptualização) da ES refletem o seu dinamismo e capacidade em poder responder às novas necessidades e problemáticas sociais, que são desafios não só das políticas sociais e de intervenção (socio)educativa, cabendo à escola uma missão determinante. São essas novas necessidades e problemáticas sociais que exigem intervenções distintas, de tal modo que fizeram surgir novos profissionais na intervenção 'social' e 'escolar'.

A. Caride (2005: 53-54) considera que a ES se carateriza por ser uma prática sujeita aos avatares que influenciam um leque de variáveis (políticas, económicas, culturais, pedagógicas, sociais) configuradoras e sustentadoras das suas intervenções. Daí a pluralidade de conceções que ela integra quando nos referimos às suas funções, espaços e/ou âmbitos ou campos de intervenção (Martins, 2013). Desta forma a ES surge em âmbitos onde normalmente não intervinha, como é o escolar, exigindo que a escola se preocupe com a ES, como forma de dar solução aos complexos problemas infantojuvenis. É um facto que o incremento de situações de alunos com dificuldades 
de adaptação à cultura escolar e suscetíveis de gerarem conflitos e problemas socioeducativos exige da ES essa atenção às problemáticas dentro da escola, envolvendo os professores nessa intervenção, em interação com outros agentes e profissionais (Petrus, 2000). Ora, a nossa reflexão vem neste sentido de uma reconceptualização da ES, num processo de (re)construção do seu papel social e dos seus âmbitos de intervenção. Reafirmamos a grande capacidade de adequação e de valorização da ES às novas necessidades e problemáticas emergentes, mesmo que implique certas dúvidas das suas funções sociais.

Por conseguinte, perante essas evidências, é preciso uma redefinição dos limites da intervenção socioeducativa (escola, comunidade), de modo a que a PS e ES promovam uma maior colaboração relacional 'comunidade-família-escola-instituições sociais' na resolução de problemáticas sociais e educativas (Trilla e tal., 2003).

\section{Reconfiguração da PS nos diálogos da educação formal e socioeducativa}

Historicamente, a identidade e evolução da 'Pedagogia' e a sua aproximação ao 'social' permitiu que se convertesse numa ciência social e pedagógica, de caráter normativo (valores), para além dos fundamentos teóricos explicativos dos processos práticos de intervenção socioeducativa e sociocultural, que no fundo são a dimensão da educação social (Martin, 2009). Ou seja, a pedagogia mantém a sua identidade como uma área científica independente de outras ciências, tendo na normatividade o princípio irrenunciável da sua justificação epistemológica, já que tem a possibilidade de elaborar normas educativas com suporte científico que Ihe proporciona as Ciências da Educação, com capacidade de validar cientificamente essas normas (autonomia como ciência) (Merino, 2005). Na verdade, a realidade educativa e comunitária fez eclodir da PS e ES múltiplas atividades e intervenções distintas, elencadas na confluência do 'educativo e/ou pedagógico' com o 'social', muito devido às origens, identidade e desenvolvimento histórico daquelas ciências (Caride, 2005). Enquanto o 'pedagógico' revela certa recuperação do sentido da 'paideia' de uma educação ao serviço das pessoas e do seu próprio desenvolvimento, o 'social' expressa a sensibilidade da educação para as necessidades de todos, principalmente dos grupos que estão em situações de conflito social (Ortega, 2005). De facto, as necessidades práticas na sociedade configuram a reflexão teórico- prática da conceptualização e paradigmas, da metodologia de intervenção e técnicas de investigação da PS e da ES (Pérez Serrano, 2003).

Desde os inícios do século passado, a Pedagogia avançou para a sua caraterização como ciência de abordagem à educação, como construção histórica e social, que apresenta sintonias ou convergências com outras ciências sociais e humanas (antropologia, sociologia, história, economia, direito, psicologia, etc.) (Caride, 2005). Lembramos que o social da educação e da pedagogia na PS, desde Natorp, precisou de 
muito tempo para renovar a sua conceção pedagógica sobre as condições sociais da educação e da vida social e, assim, segundo Caride (2009) todas as pedagogias e as suas educações são sociais, entrelaçadas nas fronteiras da teoria e práxis socioeducativa. Nessas fronteiras, as redes tecnológicas submeteram a PS à renovação, fazendo emergir a ES no âmbito dos serviços sociais e das políticas sociais e culturais (Trilla, 2000) e nas políticas educativas. Neste sentido, muitas dessas formalidades reclamaram para si a PS implicando a construção de sinais de identidade como ciência, como área científica e como profissão (Caride; Gradaílle; Belén Caballo, 2015). Ora bem, desde há muito que a PS, que sempre manteve diálogos e fronteiras com a educação não-formal, com a educação socioeducativa e sociocomunitária, se vem embrenhando no contexto escolar materializado pela ação da ES. Convém clarificar que a PS, é um conjunto de saberes que abarcam um objeto material determinado - a ES (âmbito das práticas, processos e fenómenos da realidade educativa), numa frágua de conceptualização entre 'pedagogia - educação', em que o seu adjetivo é um tipo de educação - a social, nas parcelas de ação da educação formal e da não-formal (March; Orte, 2014).

É óbvio que a PS pertence ao discurso e conhecimento pedagógicos (área das ciências da educação), num paradoxo de fundamentação epistemológica que abrange uma saga de parentesco ou 'ar de família', que são aceções (critérios) que mantêm entre si um parecido comum quando se (entre)cruzam ou se sobrepõem no universo educativo, por exemplo (Trilla, 2000: 17-37): cada personalidade humana (critério psicológico) tem nas suas diversas dimensões uma atenção educativa específica (ES), proveniente da ação de vários domínios científicos (PS), com influência (efeitos) na dimensão social - socialização e desenvolvimento da sociabilidade; a especificidade dos sujeitos da educação (critério psicossociológico), em situações de risco e/ou exclusão (marginalização, abandono, inadaptação, conflito social, infração delitiva, em perigo e outras problemáticas sociais) remete-nos para ações educativas especializadas da PS; na perspetiva dos agentes educativos e dos seus contextos (critério pedagógico), a PS ocupa-se da ES (intervenção), no âmbito da educação não-formal; em termos globais, o objeto da PS, como disciplina científica, interseta um conjunto de ações educativas (não-formais), dirigidas ao desenvolvimento da sociabilidade de pessoas e coletivos, que podem encontrar-se em situações de conflito social ou com necessidades especificas de educação; no âmbito da escola inclusiva e da sua abertura à comunidade surgiu no contexto escolar sujeitos com problemáticas de adaptação e/ou em risco em que a PS, através da ação educativa da ES tenta colaborar com outras áreas científicas na intervenção dessas situações produzidas com programas interdisciplinares 'escola-família-comunidade' (March \& Orte, 2014; Ortega, 2005; Parcerisa Aran, 2008).

Efetivamente, a PS, sendo uma área disciplinar pedagógica fundamentada na sua identidade fora do contexto escolar (âmbitos da educação não-formal), tem reproduzido um paradoxo epistemológico de que a escola não é uma instituição social (Colom, 
1987). Esta forma ilógica pôs de parte a possibilidade da PS no contexto escolar, quando esta realidade é um verdadeiro locus natural para ela. Ou seja, entendeu-se sempre a dicotomia entre a PS como uma pedagogia fora da escola e a pedagogia escolar como uma pedagogia própria de uma instituição social (March, 2007). Ambas, posições podem manter uma conexão na possibilidade de desenvolverem a ES na/desde a escola e fora dela, no círculo de formação do social (Quintana-Cabañas, 2001).

Este contributo epistemológico 'PS-Escola' tem uma grande relevância, pelo surgimento de problemas/situações escolares oriundas do seu exterior. A exigência de diálogo entre as problemáticas sociais e as possibilidades dadas pela escola é fundamental na procura de respostas. De facto, até agora as problemáticas escolares (abandono e absentismo escolar, insucesso e desmotivação para aprender, a violência e indisciplina nas aulas, o desinteresse das famílias pela escola, desapego, etc.) não eram tratadas nem tidas como problemas pedagógicos, mas sim como anomias sociais (March, 2007). Frequentemente, quando a realidade não se encaixa com a teoria e modelos educativos, a causa deve-se à realidade ou à dinâmica social que origina aqueles problemas em que a teoria educativa ou não deixou de se interessar ou criou 'pedagogias específicas' para dar solução a muitas dessas situações problemáticas (pedagogia intercultural, ambiental, para a saúde ou para o consumo, etc.) que se afastavam do discurso teórico-educativo. Ora bem retomando a relação e a conexão que se deve dar entre 'escola, pedagogia e problemática social', tendo sempre presente que a escola deve dar respostas para os problemas surgidos no seu seio, então, se a escola tenta solucionar problemáticas sociais será possível uma pedagogia social escolar. Por consequência, toda a teoria educativa terá que ser teoria social da educação, já que a escola se entronca nas problemáticas sociais e, por isso, obriga-a a ter mudanças na cultura pedagógica existente. Esta inserção entre a realidade com as suas aporias mais destacáveis, o discurso teórico e as respostas pedagógicas só é possível pelo trabalho multidisciplinar da ação ou intervenção social e escolar (Carvalho; Baptista, 2004).

Não é fácil admitir a PS como uma pedagogia contextualizada no âmbito escolar onde os modelos teóricos, o conhecimento da realidade educativa, a investigação realizada e a modificação teórica se conjuguem na procura de respostas para as suas problemáticas. Ora, isto remete-nos para um intenso diálogo entre 'teoria-prática' essencial na fundamentação de uma nova teoria para a PS, devido aos desafios socioeducativos da escola neste século, que exige uma conexão e coordenação entre 'Escola-PS' e/ou 'PS-Pedagogia escolar', já que as problemáticas sociais na escola são simultaneamente problemas sociais, em que os estudos pedagógicos sócio escolares se entrecruzam com os estudos das problemáticas socioeducativas (March; Orte, 2014). Neste sentido lembramos que já os pressupostos sociológicos da educação, indicados por Dewey, se centravam no estudo das problemáticas sociais surgidas no 
âmbito escolar, impregnadas de pragmatismo, mas que serviam para praticar pedagogia social na escola. Esta reatualização de Dewey tem um grande interesse pedagógico ao lembrar-nos que a solução para um problema social na escola exige um conhecimento social que o próprio problema já por si apresenta (Parcerisa Aran, 2008; Petrus, 2000; Trilla, 2000).

Por conseguinte, este processo de reconstrução da PS, enquanto disciplina educativa na área das ciências da educação, tem grande atualidade ao configurar a resposta social da educação para os problemas e para as necessidades sociais e educativas, numa irrupção progressiva dentro das diversas disciplinas educativas ou pedagógicas. Apesar da proliferação de diversas disciplinas especiais integrantes do campo ou áreas de intervenção da PS, a sua renovação só é possível pelo trabalho dos profissionais da ES com novos pressupostos teóricos, metodologias e ações práticas (March \& Orte, 2014).

Evidentemente que analisar a relação 'PS-Escola' leva-nos a refletir sobre as seguintes questões: o papel da ES na atualidade devido à sociedade em rede e do conhecimento produzir desigualdades e exclusões sociais, leva-a ter discurso preventivo; a incidência escolar no processo de reconfiguração da PS obriga a repensar a escola (novas funções) e a construir uma pedagogia social escolar com novas perspetivas baseadas nesse novo enfoque escolar; os desafios sociais e educativos têm impacto na escola, principalmente na qualidade, na problemática das etapas/níveis educativos, na participação da comunidade educativa, na materialização da escola inclusiva, nos perfis dos profissionais que nela atuam e na sua autonomia e gestão democrática; na relação dos serviços sociais e programas socioeducativos no seio escolar, há uma intervenção interdisciplinar onde os educadores sociais têm um papel fundamental na solução de problemas, como os conflitos, na convivência e na execução de programas; na reflexão sobre os processos de insucesso e abandono (precoce) escolar com medidas e propostas de política educativa local; na promoção da educação para a cidadania e dos direitos humanos promovendo um pensamento crítico nos sujeitos da educação; no impacto das redes sociais com a escola e na análise comunitária da realidade educativa no território educativo; no envolvimento da família com a escola - cooperação ativa e participativa (projeto educativo e atividades) no intuito de desenvolver a sua função socioeducativa, sabendo que há novas estruturas ou modelos familiares; a construção de uma pedagogia social inclusiva, equitativa e de internacionalização, como desafio permanente. 


\section{Ideias (in)conclusivas de reconsideração da Pedagogia Social Escolar}

Insistimos ao longo do texto que a educação é global, é social e realiza-se ao longo da vida (Trilla et al., 2003). Igualmente referimos que a PS se orienta para a reflexão sobre a 'intervenção' ou 'ação (componente teórica) de situações sociais/ culturais e circunstâncias existentes ou produzidas na sociedade (causas), servindo-se da ES (objeto daquela e de ação na prática de educação mais não-formal) na atividade de emancipação e desenvolvimento humano (Caride, 2005). Entendemos a ES como ação promotora e dinamizadora de uma sociedade que educa e de uma educação integral, que ajuda/apoia a evitar ou reparar dificuldades e conflitos sociais (Ruiz, 2003). De facto, a PS e a ES procuram nos novos cenários respostas incisivas sobre os problemas humanos e sociais prevenindo as suas causas, sabendo que muitos desses problemas sociais se elencam no contexto escolar (March; Orte, 2014). Por isso, a PS, ao colaborar com a escola e nos espaços socioeducativos, poderá desenvolver processos entre a 'Escola-Família-Comunidade' e outros microssistemas comunitários, em tarefas de mediação, resolução de situações de conflito social, disfuncionalidade, relações de convivência, abandono e insucesso escolar, inadaptações, às formas de analfabetismo emotivo, etc.

A ES e a educação escolar não são realidades opostas, pois a realidade é única. A própria PS, ao enveredar para o escolar, fez emergir um (novo) espaço de intervenção prática da ES, na prevenção e tratamento de situações específicas (Caride, 2015). Assim, têm surgido vários campos de intervenção da ES, com implementação de projetos e com a criação de redes sociais informativas (projeto comum de cidadania), dos quais destacamos os seguintes aspetos (Feliz Múrias, 2010): favorecer a construção da comunidade interativa e intergeracional, com especial atenção à terceira idade e à intergeracionalidade na realidade social; desenvolver espaços de intercâmbio e promoção de convivência no âmbito inter/multicultural em prol de uma cidadania (global e cosmopolita) na diversidade; promover novas atividades físicas, recreativas e desportivas, que sejam fatores de socialização e de bem-estar para a saúde dos indivíduos; intervir nas problemáticas dos imigrantes e refugiados na sociedade de acolhimento; promover os propósitos da escola inclusiva com alunos com dificuldades de adaptação; desenvolver uma educação especializada para as pessoas adultas e no âmbito empresarial; criar uma consciência de educação ambiental ao nível planetário; etc. Todas estas novas situações merecem reflexão-ação dos profissionais da ES ao nível da intervenção (novos modelos), contribuindo com a mediação na integração do indivíduo nos novos tempos/espaços que surgem na sociedade (March, 2007).

Por conseguinte, a PS - ES constituem uma 'práxis' quotidiana nos contextos socioeducativos formais e não-formais, especialmente na relação 'Escola-Família-Comunidade', mas para tal efetividade exigem-se mudanças nos estilos dos professores e 
nos modelos organizativos da escola, promovendo-se uma estreita colaboração entre o educador social e os outros técnicos ou profissionais que atuem em prol de uma aprendizagem social (Baena; Sáenz; Quintana-Cabañas, 2002).

\section{Referências Bibliográficas}

Baena, Mª Paz L.; Sáenz, J. M.M.; \& Quintana-Cabañas, J. Mª (2002). Pedagogía Social. Madrid: UNED.

Caride, J.A. ((2005). Las fronteras de la Pedagogía Social. Perspectivas científica e histórica. Barcelona: Gedisa.

Caride, J.A. (2009). Acerca de los nuevos y viejos desafíos de la educación social. Revista de Educação Pública 38, (18), 449-468.

Caride, J.A.; Gradaílle, R., \& Belén Caballo, Mª (2015). De la Pedagogia social como educación, a la educación social como Pedagogía. Perfiles Educativos - Pedagogía Social y Educación Social, 148 (XXXVII), 4-11.

Carvalho, A. D.; \& Baptista, I. (2004). Educação Social. Fundamentos e estratégias. Porto: Porto Editora.

Colom, A. J. (1983). La pedagogia social como modelo de intervención socioeducativa. Bordón, 247, 165-180.

Colom, A.J. (1987). Modelos de intervención socioeducativa. Madrid: Narcea.

Feliz Múrias, T. (2010). Diseño de programas de educación social. Madrid: UNED.

Gramigna, A. (2003). Manuale di Pedagogia Sociale (Scenari del presente e azione educativa). Roma: Armando Editore.

March [Cerdá]; \& Martí X. (2007). La educación social en el marco de la construcción del Espacio Europeo de Educación Superior. Pedagogía Social, no 14 (3), 33-52.

March [Cerdá], Martí X.; Orte [Socias], Carmen (2014). La pedagogía social y la escuela. Los retos socioeducativos de la institución escolar en el siglo XXI. Barcelona: Octaedro.

Martins, E.C. (2013). A Pedagogia social/Educação social nos meandros da comunidade e da escola. Educare et Educere, XV (1), 5-24.

Merino, J. V. (2005). Pedagogía social y educación social: Reto de conocimiento y de acción para el siglo XXI. In: J. Ruiz Berrio (ed.), Pedagogía y Educación ante el Siglo XXI (pp. 225-251). Madrid: Publ. Universidad Complutense de Madrid.

Morin, E. (2001). O desafio do Século XXI. Religar os conhecimentos. Lisboa: Instituto Piaget.

Núñez, V. (coord.) (2002). La educación en tiempos de incertidumbre: Las apuestas de la Pedagogía Social. Barcelona: Gedisa.

Ortega [Esteban], J. (2005). La educación a lo largo de la vida: la educación social, la educación escolar, la educación continua....todas son educaciones formales. Revista de Educación, 333, 167-175.

Parcerisa A. A. (2008). Educación Social en y con la institución escolar. Pedagogía Social (Revista Interuniversitária de Pedagogía Social), 15 (3), 15-27. 
Pérez Serrano, G. (2003). Pedagogía social - educación social. Construcción cientifica e intervención práctica. Madrid: Narcea.

Petrus, A. (2000). Nuevos ámbitos en educación social. In: M. Romans; A. Petrus \& J. Trilla, De profesión: educador(a) social (pp. 63-147). Barcelona: Paidós.

Quintana-Cabañas, J. Mª (2001). Pedagogía Social. Madrid: Dykinson.

Ruiz, C. (coord.). (2003). Educación social viejos usos y nuevos retos. València: Publ. Universitat de València.

Timóteo, I. (2013). A evolução da educação social: perspetivas e desafios contemporâneos. Praxis Educare (Revista da Associação dos Profissionais Técnicos Superiores de Educação Social), 1, 12-17.

Trilla, J. (2000). El universo de la educación social. In: M. Romans; A. Petrus \& J. Trilla, De profesión: educador(a) social (pp. 15-59). Barcelona: Paidós.

Trilla, J.; Gros, B.; López; F.; \& Martín, Ma J. (2003). La educación fuera de la escuela. Ámbitos no formales y educación social. Barcelona: Ed. Ariel.

Úcar, X. 2013). Exploring different perspectives of Social Pedagogy: towards a complex and integrated approach. Education Policy Analysis Archives, 21 (36), 1-17.

Ernesto Candeias Martins

Professor com agregação na área da Educação/História da Educação Social Doutor em Ciências da Educação (e Mestre em Educação). Docente no Instituto Politécnico de Castelo Branco/

Escola Superior de Educação,

Email: ernesto@ipcb.pt

ORCID: http://orcid.org/0000-0003-4841-1215;

Correspondência

Ernesto Candeias Martins

Rua Dr. António Trindade, Lote 6 3. ${ }^{\circ}$ Esquerdo 6000 - 251 - Castelo Branco (Portugal)

Data de submissão: Maio 2020

Data de avaliação: Julho 2020

Data de publicação: Novembro 2020 